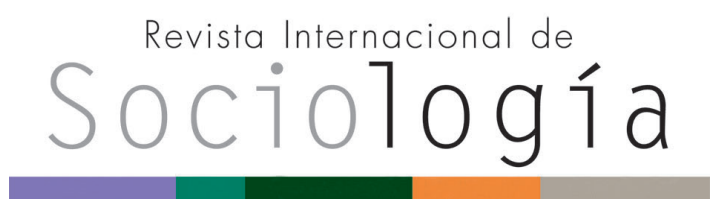

Revista Internacional de Sociología RIS

vol. 78 (1), e150, enero-marzo, 2020, ISSN-L:0034-9712 https://doi.org/10.3989/ris.2020.78.1.18.107

\title{
TRAYECTORIAS MIGRATORIAS Y FRACASO ESCOLAR DE LOS ALUMNOS INMIGRADOS Y DESCENDIENTES DE MIGRANTES EN CATALUÑA
}

\section{MIGRATION TRAJECTORIES AND SCHOOL FAILURE OF MIGRANT STUDENTS AND DESCENDENTS OF IMMIGRANTS IN CATALONIA}

\author{
JoRd BAYONA-I-CARRASCO \\ jbayona@ced.uab.es \\ ORCID iD: https://orcid.org/0000-0003-2819-9085 \\ ANDREu Domingo \\ Centre d'Estudis Demogràfics/CERCA \\ adomingo@ced.uab.es \\ ORCID iD: https://orcid.org/0000-0003-3270-1939 \\ Teresa Menacho \\ Centre d'Estudis Demogràfics/CERCA \\ tmenacho@ced.uab.es \\ ORCID iD: https://orcid.org/0000-0001-8737-9292
}

Centre d'Estudis Demogràfics/CERCA y Departament de Geografia de la Universitat de Barcelona

Cómo citar este artículo / Citation: Bayona-i-Carrasco, J., A. Domingo y T. Menacho. 2020. "Trayectorias migratorias y fracaso escolar de los alumnos inmigrados y descendientes de migrantes en Cataluña". Revista Internacional de Sociología 78(1): e150. https://doi. org/10.3989/ris.2020.78.1.18.107

\section{REsumen}

En Cataluña los cambios en la composición por origen del alumnado han sido muy intensos en los últimos años, con la entrada de menores inmigrantes internacionales, primero, y el posterior crecimiento de las segundas generaciones, provocando un fuerte aumento de la complejidad escolar. En este contexto, este trabajo cuantifica, en primer lugar, el volumen e intensidad de estos cambios, a partir de la creación de una tipología de situaciones derivadas del proceso migratorio y de la entrada en el sistema educativo, para, en un segundo momento, analizar los efectos derivados de las trayectorias migratorias sobre el fracaso escolar. Los resultados indican que los alumnos de primera generación presentan elevados niveles de fracaso escolar, y que los valores generales de fracaso observados actualmente se justifican, en parte, por un efecto composición. Al mismo tiempo, son preocupantes los niveles de fracaso observados en la segunda generación en comparación con los autóctonos.

\section{Palabras Clave}

Concentración; Escuela; Estatus migratorio; Estrategias migratorias; Inmigración.
Copyright: () 2020 CSIC. Este es un artículo de acceso abierto distribuido bajo los términos de la licencia de uso y distribución Creative Commons Reconocimiento 4.0 Internacional (CC BY 4.0).

Recibido: 26/06/2018. Aceptado: 03/07/2019

\section{Abstract}

The rapid growth in the size of the second generation of immigrants and the large-scale enrolment of descendants of international immigrants diversified the ethnic composition of students in schools in Catalonia. In this changing context, this paper first quantifies the volume and intensity of these changes through the creation of typologies of situations derived from the migratory process and the entry of migrant students into the education system. Secondly, it analyzes the impact of migration on school performance of immigrant students. The results show that first generation students have a large number of school dropouts, which can be justified by composition effect. But the school dropouts observed in the second generation are also comparatively higher than those of the native students, which is a concern for the local administration.

\section{KEYWORDS}

Concentration; Generation; Immigration; School; School failure. 


\section{INTRODUCCIÓN}

La escuela en Cataluña, y en parte del resto de España, ha conocido durante los últimos años un intenso cambio en la composición sociodemográfica de sus alumnos, hasta el punto de que más de una cuarta parte del total del alumnado matriculado actualmente en la enseñanza obligatoria está, de una forma u otra, relacionado directamente con el proceso migratorio internacional, ya sea a partir de la experiencia migratoria propia o de la biografía de sus progenitores. Esta situación, derivada del boom migratorio internacional acontecido a inicios de siglo XXI en España (Domingo y Cabré 2015; Arango 2010), representa un intenso crecimiento de la complejidad escolar si nos referimos a la composición por orígenes de los alumnos, que, al mismo tiempo, se manifiesta en un incremento de la diferenciación en la composición social de las escuelas (Síndic de Greuges 2016). En este contexto, uno de los aspectos determinantes, y que marcarán el resultado de este proceso migratorio, es la adquisición de las competencias básicas por parte de estos alumnos que favorezcan su proceso de integración. Hasta la fecha, el alumnado de origen inmigrante en España presenta habitualmente un menor rendimiento escolar (Calero y Escardíbul 2016; García Castaño, Rubio y Bouachra 2008; Huguet y Navarro 2006), situación que puede representar un freno en su proceso de integración, aumentando, como consecuencia, las situaciones de vulnerabilidad y dificultando su futura inserción y progresión en el mercado laboral. Como indican Fernández Enguita, Mena y Riviere (2010), en pleno siglo XXI las oportunidades sociales de las personas dependen cada vez más de su cualificación.

El objetivo principal de este artículo es el análisis del fracaso escolar de la población en edad escolar surgida de la inmigración, entendiendo como fracaso la no superación de los estudios mínimos obligatorios en España. Las principales aportaciones del mismo se deben a su carácter exhaustivo, ya que, por primera vez en Cataluña, se emplean microdatos de todos los alumnos, y a la reconstrucción de una tipología generacional, que permite analizar el logro académico en función del historial migratorio propio o de los progenitores, lo que permite un análisis detallado de los descendientes. Para ello, se cuenta con los microdatos de los alumnos matriculados en la enseñanza no universitaria en Cataluña durante el curso 2015-2016, cedidos por el Departament d'Ensenyament de la Generalitat de Catalunya. Estos datos, mediante un convenio con el Institut d'Estadística de Catalunya (Idescat), se han enlazado con el Registro Estadístico de Población ${ }^{1}$, lo que nos permite reconstruir para todos los alumnos una tipología de situaciones, a las que hemos llamado "estatus migratorio", que relaciona el proceso migratorio de los alumnos con el de sus progenitores. Para este paso, es esencial la identificación en los registros escolares de los progenitores de los alumnos, que ha permitido su posterior localización en el Registro Estadístico de Población ${ }^{2}$. Con ello, y siguiendo los trabajos de Rumbaut (2004), se ha creado una tipología compuesta por cinco grandes grupos, en función del momento de llegada propio o del origen de sus progenitores (autóctonos, primera generación, generación 1,75, segunda generación y generación 2,5). A pesar de que la nomenclatura por "generaciones" haya sido criticada, ya que los hijos de los inmigrantes nacidos en el país de recepción siguen siendo, bajo este criterio, categorizados incorrectamente como "inmigrantes", con lo que se puede contribuir, en cierta forma, a su posible estigmatización, su amplia popularización académica justifica su utilización ${ }^{3}$. Rumbaut (2004) incluso añade nuevas categorías (utiliza la generación 1,25 para referirse a los llegados entre los 13 y 17 años de edad). Empleando esta tipología, la cuantificación de las distintas situaciones relacionadas con el proceso migratorio se constituye como el primer objetivo de este trabajo.

Más adelante, y priorizando las consecuencias derivadas del proceso migratorio de los alumnos, se analiza el fracaso escolar. Desde esta perspectiva, se considera el amplio abanico de situaciones derivadas del propio proceso migratorio, que muchas veces no se contemplan en los análisis sobre los alumnos de origen inmigrante. El año de llegada, la interrupción temporal debida a un movimiento migratorio de retorno parcial durante unos años al país de origen (lo que aquí se denomina "discontinuidad"), o la convivencia con los progenitores son ejemplos de ello. La escasez de datos sobre las trayectorias migratorias (muchas veces, en las estadísticas, solo consta la nacionalidad o el lugar de nacimiento), ha favorecido interpretaciones que focalizan el fracaso en el origen de los inmigrados, tendiendo a establecer comparaciones entre las expectativas familiares de unos grupos u otros. Como demógrafos, creemos que, como paso previo al análisis de causalidades "culturalistas", debe tomarse en cuenta la perturbación que las propias pautas migratorias provocan en el rendimiento escolar. Finalmente, nos interesa analizar la concentración escolar como un elemento más que condiciona ese rendimiento, directamente asociado a las condiciones socioeconómicas con las que viven esos alumnos y lo que se ha llamado "efecto barrio".

Este trabajo centra su atención en Cataluña, donde encontramos, desde años atrás, un volumen muy importante de inmigrantes extranjeros, caracterizados por una elevada diversidad de orígenes. El carácter pionero de la inmigración internacional, en comparación con otras regiones españolas, significa la existencia de un volumen importante de descendientes de inmigrantes, las segundas generaciones, con un creciente número de alumnos que finalizan ya la educación obligatoria. 


\section{INMIGRACIÓN Y FRACASO ESCOLAR}

Los efectos del boom migratorio internacional de inicios de siglo sobre la composición del alumnado de las escuelas españolas fueron reconocidos inmediatamente, por la entrada de jóvenes inmigrantes arrastrados por los procesos migratorios de sus padres (Alegre, Benito y González 2006; Carrasco 2003; Colectivo IOE 2003, entre muchos otros). Poco más tarde, se añadieron los procesos de reagrupación familiar motivados por el progresivo asentamiento y regularización de los inmigrados (Alcalde et al. 2010), provocando un nuevo aumento del crecimiento del número de alumnos extranjeros. Este periodo de intenso incremento de los flujos puede darse por finalizado a partir del curso 2008-2009, cuando empiezan a vislumbrarse las consecuencias de la crisis económica. En el caso de Cataluña y para la enseñanza no universitaria, se observa una reducción inicial del ritmo de crecimiento de los alumnos extranjeros y su posterior estabilización, aunque el volumen máximo se alcanza en 2011-2012 con 168 575 alumnos. Desde entonces, se produce un descenso de baja intensidad, situando las cifras del curso 2016-2017 en 159509 alumnos ${ }^{4}$. Con relación al alumnado total, estas cifras representan la transición desde un 5,3\% de los alumnos en el curso 20022003 al 13,2 \% del 2008-2009, para situarse actualmente en un $12,2 \%$, porcentajes fuertemente condicionados por el acceso diferencial a la nacionalidad española de los alumnos 5 . Pero también este impacto se produce de forma diferida. En la actualidad, el cambio en la composición respecto a la migración del alumnado se realiza mayoritariamente a través de la incorporación de los hijos de inmigrantes, las llamadas "segundas generaciones", algunas de las cuales conservan la nacionalidad de sus padres, mientras otras quedan invisibilizadas desde la perspectiva de la nacionalidad.

La propia medida de los resultados escolares es ya, por sí misma, controvertida. Si bien la mejor manera de analizar el rendimiento es a partir del análisis de la adquisición de determinadas competencias por parte de los alumnos, esto no es siempre posible. Siguen esta dirección los estudios realizados a partir de los datos del informe PISA ${ }^{7}$, en que se analizan las competencias básicas adquiridas por los alumnos de 15 años de edad, pudiéndose diferenciar los resultados entre autóctonos e inmigrantes de primera y segunda generación, aunque sin poder distinguir a los inmigrantes según su origen o nacionalidad. También el éxito o fracaso escolar puede ser medido a través de otras variables, ya sea estudiando las competencias adquiridas en otros cursos, el porcentaje de repetidores o el porcentaje de menores con 11 y 15 años que cursan sexto de primaria y cuarto de ESO respectivamente (es decir, el curso que tocaría según su edad), lo que se conoce como "tasa de idoneidad" (Bolívar y López-Calvo 2009). A pesar de las diversas aproximaciones, habitualmente el concepto de fracaso escolar se construye empleando el porcentaje de alumnos que no obtienen el título acreditativo de la educación obligatoria mínima, en el caso de España, el graduado de ESO. Esta acepción, aún siendo conscientes de que no es la mejor medida, es la que se emplea en este trabajo y en las comparativas internacionales (Departament d'Ensenyament 2013).

Generalmente, en la explicación del logro educativo se consideran tres grandes grupos de motivos: personales, familiares y escolares. Entre los primeros, se identifica la repetición de curso o el sexo de los alumnos. La repetición acostumbra a ser poco exitosa y se relaciona con el abandono y el fracaso escolar (Martínez García 2009), mientras que las chicas sistemáticamente obtienen mejores resultados. Fernández Enguita, Mena y Riviere (2010) exponen varios motivos para este mayor éxito educativo, desde una cuestión biológica del proceso de desarrollo a una mejor actitud o una menor conflictividad relacionada con los roles de género en la escuela. En el caso particular de alumnos de origen inmigrado, la edad en el momento de llegada es una de las variables personales más relacionadas con el éxito escolar (Böhlmark 2008).

Entre los segundos, los motivos familiares, es determinante el nivel educativo de los progenitores, su actividad laboral, la categoría socioeconómica en la que se encuadran y el origen o nacionalidad. Ya a partir del informe Coleman (1966), se identifica un fracaso escolar superior en las clases sociales más bajas. Esta asociación entre clase social y resultados escolares es también comprobada para el caso español (Fernández Mellizo y Martínez García 2017). En cuanto a los alumnos de origen inmigrante y sus descendientes, la mayor pertenencia a estas clases sociales menos favorecidas explica parte del fracaso escolar.

Finalmente, en la categoría de los motivos escolares se encuentran las características de los centros, los recursos disponibles y la composición por origen de los mismos. La titularidad (pública o privada) ha sido subrayada en España debido a la desigual distribución del alumnado por origen, aunque es la segregación respecto al resto de alumnado (LópezFalcón y Bayona, 2012; Murillo y Martínez-Garrido, 2018) y la concentración de la población inmigrada en la escuela la que capta mayor atención. En este sentido, Garrido y Cebolla-Boado (2010) identifican cuatro grandes grupos de causas que, en la literatura internacional, relacionan la concentración con el fracaso escolar: 1) la composición socioeconómica de las familias en los centros de mayor concentración de población inmigrante; 2) los efectos de escuela, pues, en algunos casos, la localización de la escuela significa la existencia de reducidos medios económicos, con menores recursos materiales, pero también humanos y que, en el caso de España, como se ha mencionado, puede relacionarse con la titularidad, 
pública o privada, de la misma; 3 ) los efectos de grupo o clase, especialmente si se distribuye a los alumnos en diferentes grupos en función de sus características o resultados previos, y, finalmente, 4) las micro interacciones en centros con concentración de inmigrantes, por el efecto contagio que provoca un impacto negativo sobre el rendimiento escolar. Estos efectos, una vez controladas las características sociales de los alumnos, son generalmente débiles y en el caso de España, únicamente se observan en escuelas con concentraciones de alumnos inmigrantes por encima del $20 \%$ (Cebolla-Boado y Garrido 2011, analizando datos del informe PISA 2006). Calero y Escardíbul (2016), por su parte, identifican el mismo efecto concentración sobre los resultados escolares, que, en este caso, afecta tanto a los inmigrantes como a los alumnos autóctonos. Con datos de 2012, las consecuencias sobre los resultados se producen a partir de niveles significativos de concentración, del $30 \%$ para los alumnos autóctonos y del $40 \%$ entre los alumnos de origen inmigrante.

Fernández González y Rodríguez Pérez (2008) agrupan todos estos motivos como factores socioestructurales. Además de ellos, existirían otros dos grandes grupos de factores, los relacionados con el capital humano y con el capital cultural. Entre los primeros, destaca la dedicación de los progenitores o la misma elección de centro escolar por parte de estos. Entre el capital cultural, sobresale la posición del estudiante en la estructura de clases, en que las clases altas son más proclives a transformar su capacidad económica en mejores resultados académicos y con mayores expectativas de los progenitores.

En general, los alumnos de origen inmigrante acostumbran a presentar menores rendimientos académicos que los alumnos autóctonos (OCDE 2016). En el caso de España, los trabajos basados en los datos PISA identifican un riesgo más elevado de fracaso escolar entre los alumnos inmigrantes (Choi y Calero 2013), que incluso llegan a duplicar los porcentajes de fracaso de los autóctonos (Calero, Choi y Waisgrais 2010). Para Cataluña, los datos del informe PISA reafirman los peores resultados obtenidos por los alumnos inmigrados (Bonal et al. 2015), situándose entre las CC. AA. de España y entre los países europeos donde las diferencias son mayores en relación con los autóctonos (Albaigés y FerrerEsteban 2017). En el mismo sentido, las estadísticas del Departament d'Ensenyament sobre la consecución del graduado de ESO desde la perspectiva de la nacionalidad insisten en esta mayor incidencia del fracaso (Domingo y Bayona 2016).

Desde otra perspectiva, Aparicio y Portes (2014) analizan las segundas generaciones (definidos como los hijos de los inmigrados), en las que, no obstante los buenos rendimientos escolares observados, se identifica un elevado riesgo de resultados negativos entre los alumnos incorporados al sistema educativo cuanto mayor es la edad, o entre algunos grupos nacionales con escaso capital humano de los padres. De Miguel y Solana (2017) también encuentran un peor rendimiento escolar de los alumnos inmigrados y de los descendientes de inmigrados, especialmente para aquellos que provienen de países del norte de África, en este caso analizando los años de escolarización. Estos malos resultados escolares se producen a pesar de que, en general, las aspiraciones educativas de los alumnos inmigrados sean mayores que las de los autóctonos (Gil-Hernández y Gracia 2018).

\section{HIPÓTESIS DE LA INVESTIGACIÓN}

La principal hipótesis de este artículo es que los bajos rendimientos académicos de los menores de algunas de las nacionalidades más representadas en Cataluña pueden derivarse de los propios procesos migratorios que afectan a la escolarización del menor, como la edad de entrada al sistema y su permanencia en el mismo. De esta forma, factores estrictamente demográficos, relacionados con las estrategias migratorias, inciden negativamente en los resultados escolares.

\section{Datos, VARiables y metodología}

Como se ha avanzado, contamos con microdatos de 1224755 alumnos, de los que se dispone de sus principales variables estadísticas, entre las que se encuentran las relativas al éxito escolar, y de algunas variables sobre las escuelas, como su titularidad y localización. En particular, se ha prestado especial atención a 1007473 alumnos que cursan el segundo ciclo de infantil, primaria y secundaria, que forman nuestro universo de análisis ${ }^{8}$. Mediante un convenio con el Institut d'Estadística de Catalunya (Idescat) estos datos han sido cruzados con el Registro Estadístico de Población, operación estadística basada en el Padrón Continuo que integra toda la información estadística administrativa. Con este enlace ha sido posible recuperar algunas variables, como la nacionalidad y el país de nacimiento de los progenitores de los alumnos y también la convivencia con ellos. Asimismo, se dispone de la fecha de primera y última entrada del alumno en el registro padronal en $\mathrm{Ca}-$ taluña9. La comparación de ambas fechas se ha utilizado para definir la situación de discontinuidad en la residencia en Cataluña y, por ende, en el sistema escolar ${ }^{10}$. Esta variable es de notable interés en el análisis de algunos colectivos nacionales que utilizan con los hijos estrategias propias de reproducción cultural que implican el retorno temporal al país de origen. Al mismo tiempo, la discontinuidad también puede informar de retornos selectivos durante un periodo temporal en relación con la situación de crisis económica, práctica que puede ser importante en algunos orígenes (García Balles- 
teros, Jiménez Blasco y Mayoral 2014). Por otra parte, la fecha de entrada, en relación con la edad del alumno, se emplea para identificar a aquellos alumnos que se han incorporado al sistema educativo desde su inicio, en comparación con aquellos que lo han hecho con posterioridad.

A partir de estos enlaces se clasifican los alumnos en función de las características del propio proceso migratorio o del de sus progenitores, combinando el lugar de nacimiento del alumno, la edad con la que llegaron a Cataluña y el país de nacimiento de sus progenitores. Con ello se consigue la siguiente categorización (tabla 1):

1) Primera generación (o generación 1): son los alumnos nacidos en el extranjero y llegados a Cataluña con siete o más años de edad y que, por lo tanto, no se incorporan al sistema educativo desde su inicio;

2) Generación 1,75: también son alumnos nacidos en el extranjero, aunque en este caso han llegado a Cataluña con menos de siete años de edad $y$, por lo tanto, empiezan su escolarización obligatoria en el lugar de destino;

3) Segunda generación: alumnos nacidos en España con ambos progenitores (o uno, en caso de tener información de solo uno de ellos) nacidos en el extranjero;

4) Generación 2,5: alumnos nacidos en España con uno de sus dos progenitores nacido en el extranjero y el otro en España, y

5) Autóctonos: se identifica como tales a los alumnos nacidos en España con ambos progenitores igualmente nacidos en España (o uno, en caso de tener información de solo uno de ellos) ${ }^{11}$.

No se dispone de la información completa para todo el alumnado. Cuando, a pesar de la falta de datos, se sabe que son nacidos en el extranjero, son categorizados como "otros inmigrantes".

El fracaso escolar se analiza para los 42797 alumnos matriculados en cuarto de ESO y en institutos públicos. Esto implica un sesgo en los resultados con relación al total, aunque debemos tener en cuenta que en estos institutos se concentra prácticamen- te el $75 \%$ del alumnado relacionado con el proceso migratorio. El cálculo del fracaso se ha realizado en relación con los alumnos matriculados en el último curso de ESO, cálculo que puede minimizar la incidencia del mismo fracaso, ya que no recoge a los alumnos que no han alcanzado dicho curso y han abandonado el sistema con anterioridad a superar la edad de escolarización obligatoria.

Después de una primera descripción del alumnado, se ha empleado un modelo de regresión logística para el análisis de los factores que inciden en mayor o menor medida en la propensión al fracaso escolar. En un segundo momento, se realizan cinco modelos específicos, teniendo en cuenta la clasificación del estatus migratorio. Para la elaboración de los modelos particulares se han contemplado las mismas variables que para el modelo global, incluyendo en este el propio estatus migratorio de los alumnos como factor explicativo, y exceptuando el año de llegada y el continente de nacimiento para aquellos alumnos que han nacido en España. De esta manera, podemos evaluar cómo afectan todos estos factores al conjunto de alumnos y caracterizar las particularidades de los alumnos según su estatus.

Se ha aplicado un análisis multivariante mediante un modelo de regresión logística en que la variable dependiente es "No obtener el título de $4 .^{\circ}$ ESO". De esta forma, se obtiene la propensión al fracaso (empleando odds ratio), controlando por una amplia batería de variables, derivándose un perfil de variables que influyen en cada caso, porque sabemos cómo actúan los distintos factores influyentes. Con esta metodología, los resultados eliminan los efectos de estructura.

Los factores considerados en las regresiones son los siguientes:

1) La tipología del estatus migratorio, diferenciando autóctonos, primera generación, generación 1,75 , segunda generación y generación 2,5 .

2) El sexo (hombres y mujeres). Se trata de una de las variables que afectan más al rendimiento escolar, e incluso entre los inmigrantes se observan resultados claramente mejores en las chicas (Colectivo IOÉ 2003).

Tabla 1.

Composición del alumnado según la tipología generacional en Cataluña en el curso 2015-2016

\begin{tabular}{|lcccccccc|}
\hline & $\begin{array}{c}\text { Primera } \\
\text { generación }\end{array}$ & $\begin{array}{c}\text { Generación } \\
\mathbf{1 , 7 5}\end{array}$ & $\begin{array}{c}\text { Segunda } \\
\text { generación }\end{array}$ & $\begin{array}{c}\text { Generación } \\
\mathbf{2 , 5}\end{array}$ & Autóctonos & $\begin{array}{c}\text { Otros } \\
\text { inmigrantes }\end{array}$ & Otros & Total \\
\hline Alumnado & 24236 & 46593 & 133238 & 54940 & 721121 & 10254 & 17091 & 1007473 \\
$(\%)$ & 2,4 & 4,6 & 13,2 & 5,5 & 71,6 & 1,0 & 1,7 & 100,0 \\
\hline
\end{tabular}

Fuente: elaboración propia. Datos del Departament d’Ensenyament e Idescat, curso 2015-2016. 
3) El país de nacimiento. Se considera, por un lado, España y, por otro, los demás países en agrupaciones continentales (Europa, África, América, Asia, y Otros). El lugar de origen es importante con relación al conocimiento de la lengua castellana, especialmente entre los hispanoamericanos (Huguet, Navarro y Janés 2007), pero también es un marcador de la estigmatización de ciertos colectivos (Cea d'Ancona y Valles 2014).

4) La nacionalidad, diferenciando entre la española y el resto, agrupadas según el continente de nacionalidad (Europa, África, América y Asia). Esta se incluye debido a que puede ser importante para aquellos nacidos en España o llegados muy pequeños, ya que el acceso a la nacionalidad española es desigual según el origen (Álvarez 2006).

5) El año de llegada a Cataluña. Para los alumnos nacidos fuera de Cataluña, se han definido las siguientes categorías: nacido en Cataluña y sin movimiento alguno, llegados antes de 2006, llegados entre 2006 y 2011, llegados entre 2011 y 2014 y llegados en el último año (2015). Son categorías pensadas para que se aproximen, en el caso de los alumnos de cuarto de Secundaria, a las edades correspondientes con las distintas etapas educativas.

6) La discontinuidad. La discontinuidad se categoriza a partir de aquellos alumnos en los que el año de primera y última llegada a Cataluña no coinciden; también para los nacidos en Cataluña cuando existe una nueva llegada. En el hipotético caso de movimientos inferiores al año (y si este fuera el mismo), se considera continuo.

7) Las necesidades educativas especiales (NEE). Se trata de una categoría que clasifica al alumno en función de si requiere una atención específica en el aula. En este caso, se diferencia entre la categoría de situación social desfavorable y el resto de posibilidades. No se contempla la categoría de llegada tardía, pues esta ya se encuentra controlada por el año de llegada a Cataluña. Esta es la única variable de rango socioeconómico disponible.

8) La concentración. Se define a partir de la representatividad sobre el total de la suma de todos los alumnos relacionados con el fenómeno migratorio, ya sea por propia migración o por migración de sus ascendientes. Se calcula para el último curso de ESO. Se utilizan cinco categorías, agrupando la concentración según quintiles, con el quintil 3 (alrededor de la mediana) como referencia.

9) La convivencia con los progenitores. Variable derivada del Padrón continuo de población, ya que informa de la presencia de los progenitores en el hogar. En este caso, se consideran las siguientes categorías: convivencia con los dos progenitores, con la madre, con el padre, con otras personas. Generalmente, se argumenta que los niños que no conviven con ambos progenitores obtienen peores resultados (McLanahan, Tach y Schneider 2013), aunque las diferencias con las familias de dos progenitores son pequeñas cuando se controla por las características socioeconómicas (Boertien 2018). Entre las familias inmigrantes, las distintas estrategias migratorias se relacionan con una mayor complejidad en la situación familiar (Domingo y Bayona 2010).

10) La repetición de curso. Se trata de la posibilidad de que el alumno esté repitiendo curso (repetidor o no repetidor).

\section{Algunos APUNTES SOBRE EL PROCESO MI- gratorio en Cataluña}

Si bien los primeros flujos migratorios internacionales de cierta entidad llegados a Cataluña son registrados a finales de los años setenta e inicios de los ochenta, no será hasta finales de siglo XX e inicios del siglo XXI cuando se conozca una intensificación de los mismos. De apenas 253050 personas y un 4,0 $\%$ de la población total de Cataluña en el año 2000, las cifras superan el millón de personas en 2007 (1 070438 y el $15,0 \%$ ) y alcanzan máximos en 2010 con 1291341 personas y el $17,3 \%$ de la población $^{12}$. Durante estos años, la progresiva maduración del proceso migratorio, coincidiendo con la bonanza económica, comporta un aumento de los procesos de reagrupación familiar, en los que, a pesar de que los menores son protagonistas, se han identificado estrategias de reagrupación encaminadas a la futura inserción en el mercado laboral (Domingo, LópezFalcón y Bayona 2010), lo que conlleva diferencias en el volumen de efectivos según el sexo y una entrada en edades próximas a los máximos legales. A finales de 2008 la situación cambia bruscamente. Como consecuencia de la crisis económica, se registra un descenso del número de inmigrantes entre 2010 y 2015 (hasta un mínimo de 1150450 y el 15,6 \% de la población). Además del descenso de las llegadas, se produce un crecimiento de las salidas (Ortega-Rivera, Domingo y Sabater 2016), con un aumento de los retornos y de reemigraciones hacia otros países europeos que, en casos de extrema vulnerabilidad, puede afectar directamente a los menores, ya que en momentos de estrecheces económicas pueden ser enviados con la familia en origen (García-Ballesteros, Jiménez Blasco y Mayoral 2014). Finalmente, y durante los últimos años, se empieza a observar una lenta recuperación de las altas por inmigración, reflejo de la incipiente mejora económica.

En este contexto, y a pesar de esta evolución general, algunos orígenes emergentes han conocido durante esta época crecimientos continuos en sus efectivos $y$, aunque tengan una menor implantación entre la población inmigrante en Cataluña, se encuentran entre los orígenes más presentes en la escuela, 
como es el caso de los alumnos hondureños y otros de Centroamérica con una presencia importante entre los alumnos de primera generación. Por otro lado, en los últimos años un porcentaje muy importante de los nacimientos en Cataluña han sido de padres extranjeros. Desde 2000 a 2008, por ejemplo, los nacimientos de madre extranjera se multiplican desde los 5707 a los 25075 , y del $9 \%$ de los nacimientos al $28,2 \%$. Desde entonces, se observa una reducción de su volumen, hasta los 18293 de 2016 (el 26,5\%). $\mathrm{Si}$ se considera la nacionalidad de ambos progenitores, la representatividad aumenta hasta el $32,5 \%$ de los nacimientos en 2016, con 22368 nacimientos de un padre o madre de nacionalidad extranjera.

\section{Características migratorias de los ALUMNOS SEGÚN SU ESTATUS MIGRATORIO}

Los vaivenes económicos y su repercusión sobre los flujos migratorios, pero también la fecundidad, determinan la composición por origen de los alumnos. Desde la perspectiva del proceso migratorio, las diferencias entre cursos en los perfiles de los alumnos son muy acusadas, pero también según la titularidad de la escuela. Mientras en los primeros cursos los alumnos pertenecientes a las segundas generaciones son la situación más representada, por detrás de los autóctonos (figura 1), en los últimos cursos de la ESO adquieren mayor visibilidad el alumnado de la primera generación y de la generación 1,75 . Esta situación es especialmente visible en la escuela pública, que concentra a los recién llegados (el 80,5\% de la primera generación en el último curso de ESO).
A pesar de la posible continuidad en las entradas de alumnos que se pueda producir en un futuro, el perfil de los alumnos que llegarán durante los próximos años al final de la educación obligatoria cambiará de forma ostensible, adquiriendo un mayor peso las segundas generaciones.

Debido a esta elevada diversidad, el análisis del fracaso se realiza para un grupo de alumnos en que la composición por origen de los no autóctonos es aún muy heterogénea. De los 42797 alumnos de cuarto curso de ESO que estudian en escuelas públicas, un $68,7 \%$ son autóctonos, es decir, que tanto el alumno como sus progenitores son nacidos en España. Los alumnos que se encuentran relacionados con el fenómeno migratorio suman un $30 \%$, en su mayoría pertenecientes a la primera generación (tabla 2). Cuantitativamente, la generación 1,75 sigue siendo mayor que la segunda generación ( $8,6 \%$ y $5,1 \%$ de los alumnos), mientras que la generación 2,5 tiene menor importancia (el 3,6 \%).

En cuanto a sus características (tabla 2), y en comparación con los autóctonos, el alumnado de primera generación se encuentra ligeramente masculinizado, mientras que tanto en la generación 1,75 como en la segunda generación hay un mayor número de mujeres. En el primer caso, la masculinización se origina en fuertes desequilibrios en algunos orígenes a favor del sexo masculino (pakistaníes e indios, por ejemplo), lo que puede estar reflejando tanto desequilibrios por sexo en el nacimiento en el país de origen como una estrategia de reagrupación

Figura 1.

Proporción que representan los alumnos según su estatus migratorio y la titularidad de la escuela en Cataluña en el curso 2015-2016

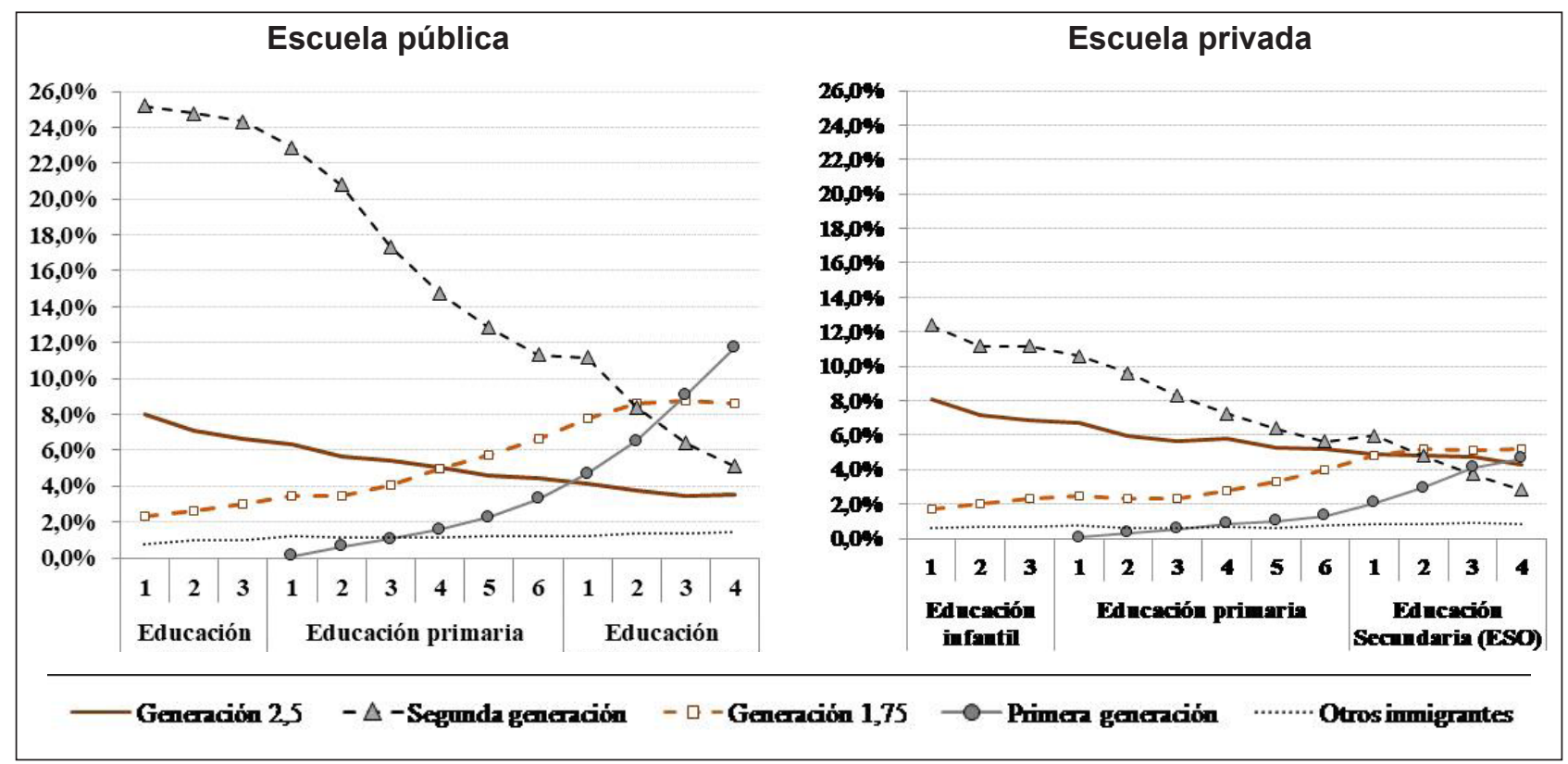

Fuente: elaboración propia. Datos del Departament d’Ensenyament e Idescat. 
familiar en la que se prima al sexo masculino, pensando en una futura inserción laboral al alcanzar la edad legal. En el segundo caso, esta diferencia se debe a un efecto selección, por el abandono de la escuela de algunos chicos al alcanzar los dieciséis años de edad, como se insinúa para los marroquíes o gambianos ${ }^{13}$.

En cuanto a la nacionalidad, el 49,2\% de los alumnos relacionados con la inmigración tienen la nacionalidad española, ya sea de origen o bien adquirida posteriormente, valores que oscilan entre el mínimo del $21,6 \%$ de la primera generación y el 99,7 \% de la generación 2,5. Entre los alumnos de la generación 1,75 , la nacionalidad ha sido adquirida en el $48,6 \%$ de los casos, mientras que para la segunda generación, a pesar de haber nacido en España, un 21,9 \% sigue manteniendo una nacionalidad extranjera.

Una de las variables asociadas al proceso migratorio es la posible existencia de discontinuidades en la presencia en Cataluña. Por definición, la discontinuidad conlleva una salida fuera de Cataluña (que se define a partir de las diferencias entre año de primera y última llegada), aunque desconocemos si esta salida es hacia otra CCAA o al extranjero, y también su extensión temporal. Por lo tanto, únicamente conocemos la existencia de una suspensión en la permanencia en el sistema educativo catalán. Así definida, la discontinuidad afecta al 7,5 \% de los alumnos. Según el estatus migratorio su incidencia es desigual, siendo especialmente importante en la generación 1,75 (el 20,8 \%), pero también en la segunda generación (el 15,2 \%). En la primera generación el impacto es menor, en parte por un efecto de selectividad estadística, ya que se dispone de menos tiempo para que esta situación se produzca. La discontinuidad se observa con mayor intensidad entre marroquíes, paquistaníes, ecuatorianos, bolivianos y chinos, y, al contrario de lo que cabría esperar, se observan pocas diferencias entre sexos. Las causas pueden ser diversas: por un lado, es una forma de ahorro económico en situaciones de inestabilidad, pero también una estrategia de disminución de la aculturación de la descendencia, que permita mantener la lengua, la cultura y los valores.

Se ha añadido al análisis la posibilidad de que el alumno esté incluido dentro de la categoría de necesidades educativas especiales, en particular nos interesa la existencia de una situación social desfavorable. A pesar de que su peso alcanza tan solo el $8,5 \%$ de los alumnos de segunda generación, como valor más destacado, se ha recuperado esta variable por ser la única que nos proporciona alguna información sobre la situación económica familiar, que acostumbra a ser una de las principales variables sociodemográficas explicativas del fracaso escolar, como vertiente económica de la clase social.

En cuanto a la convivencia familiar, las categorías relacionadas directamente con la inmigración mues- tran proporciones sensiblemente inferiores de convivencia con ambos progenitores. Estos datos deben observarse con precaución, ya que pueden acumular errores producto de la mayor complejidad en el empadronamiento de los inmigrantes, desconociéndose cuál es su fiabilidad. Incluso en el caso particular de la generación 2,5, puede existir un efecto de selección (la existencia de progenitores nacidos en y fuera de España), lo que justifica los mayores valores de convivencia observados.

La composición del alumnado según el año de llegada indica que un $10,6 \%$ de los alumnos de la primera generación habría llegado durante el último año, y un elevado $30 \%$ durante los cursos pertenecientes a la ESO, siendo, por lo tanto, serios candidatos a un menor rendimiento escolar, especialmente si hay diferencias en el idioma. Se tiene también en cuenta la posibilidad de que el alumno esté repitiendo curso. Esta situación presenta valores elevados en los dos grupos de inmigrantes, del 13,3 \% y el $7,3 \%$. En cuanto a la concentración, esta se construye a partir de la presencia en el centro escolar de cualquiera de las categorías relacionadas con la inmigración (y no únicamente la nacionalidad o el país de nacimiento). Para su análisis, se dividen los datos en quintiles, observándose un crecimiento de la presencia de algunos grupos a medida que aumenta la concentración, especialmente de los alumnos de primera generación. La generación 2,5 se comporta de forma muy similar a los autóctonos, mientras que los porcentajes de la generación 1,75 y la segunda generación son muy parecidos, en ambos casos con una evidente mayor concentración que los alumnos autóctonos.

Finalmente, es importante que se considere el país de nacimiento en el caso de los nacidos en el continente americano, ya que su presencia se desdibuja según la nacionalidad, como sucede con la generación 1,75 (son el 50,7 \% de la generación 1,75 por lugar de nacimiento, pero solo el 14,8 \% según la nacionalidad).

\section{El fracaso escolar}

En Cataluña, y durante el curso 2015-2016, alrededor de uno de cada siete alumnos matriculados en escuelas públicas ${ }^{14}$ en el último curso de secundaria no conseguía alcanzar el título de graduado en ESO (tabla 3), con diferencias evidentes según el sexo (17,5\% para los hombres y $10,5 \%$ entre las mujeres). El estatus migratorio añade un factor de diferenciación significativo y gradual, desde los máximos de los alumnos de primera generación, en que tres de cada diez alumnos no alcanzaban el graduado (29,3 $\%$ ) hasta la generación 2.5 , que conocen resultados incluso más favorables que los de los alumnos autóctonos (10,1\% por el 10,3\% de los autóctonos). Además, a mayor fracaso escolar, mayores son las diferencias entre sexos, y siempre con mejores resultados para las chicas. 
Tabla 2.

Principales características de los alumnos del último curso de ESO según el estatus migratorio en las escuelas públicas de Cataluña en 2015-2016

\begin{tabular}{|c|c|c|c|c|c|c|}
\hline & Autóctonos & $\begin{array}{c}\text { Primera } \\
\text { Generación }\end{array}$ & $\begin{array}{c}\text { Generación } \\
1,75\end{array}$ & $\begin{array}{l}\text { Segunda } \\
\text { Generación }\end{array}$ & $\begin{array}{c}\text { Generación } \\
2,5\end{array}$ & Total \\
\hline Total alumnos & 29384 & 5014 & 3695 & 2188 & 1525 & 42797 \\
\hline (\%) & 68,7 & 11,7 & 8,6 & 5,1 & 3,6 & 100,0 \\
\hline \multicolumn{7}{|l|}{ Sexo } \\
\hline$\%$ Mujeres & 49,5 & 48,2 & 52,4 & 52,0 & 50,2 & 49,7 \\
\hline \multicolumn{7}{|l|}{ Discontinuidad } \\
\hline Discontinuos & 4,5 & 12,7 & 20,8 & 15,2 & 4,4 & 7,5 \\
\hline \multicolumn{7}{|c|}{ Necesidades Educativas Especiales } \\
\hline Situación social desfavorable & 1,7 & 6,2 & 5,4 & 8,5 & 1,6 & 3,0 \\
\hline \multicolumn{7}{|c|}{ Convivencia con los progenitores } \\
\hline Los dos & 62,7 & 32,5 & 46,0 & 46,3 & 77,8 & 56,3 \\
\hline Madre & 28,4 & 33,4 & 29,7 & 34,1 & 16,7 & 28,5 \\
\hline Padre & 5,7 & 15,8 & 9,7 & 15,3 & 4,1 & 7,7 \\
\hline Otros & 3,0 & 3,0 & 2,4 & 3,4 & 1,2 & 2,8 \\
\hline Se desconoce & 0,2 & 15,3 & 12,2 & 1,0 & 0,2 & 4,7 \\
\hline \multicolumn{7}{|l|}{ Año de llegada a Cataluña } \\
\hline No se ha movido & 97,9 & 0,0 & 0,0 & 93,9 & 97,4 & 76,5 \\
\hline Antes de 2006 & 0,9 & 1,7 & 88,3 & 3,4 & 1,4 & 8,4 \\
\hline Entre 2006 y 2011 & 0,3 & 57,5 & 11,6 & 1,2 & 0,3 & 8,0 \\
\hline Entre 2011 y 2014 & 0,2 & 30,2 & 0,0 & 0,6 & 0,1 & 3,7 \\
\hline Último año & 0,1 & 10,6 & 0,0 & 0,1 & 0,1 & 1,3 \\
\hline \multicolumn{7}{|l|}{ Repetición } \\
\hline Es repetidor & 4,4 & 13,3 & 7,3 & 5,8 & 3,8 & 5,8 \\
\hline \multicolumn{7}{|l|}{ Concentración } \\
\hline Quintil 1 & 24,2 & 5,8 & 9,1 & 8,6 & 21,2 & 19,5 \\
\hline Quintil 2 & 23,4 & 11,2 & 14,0 & 13,6 & 21,4 & 20,3 \\
\hline Quintil 3 & 20,6 & 15,9 & 19,1 & 17,4 & 19,5 & 19,6 \\
\hline Quintil 4 & 18,8 & 22,5 & 23,6 & 25,0 & 22,3 & 20,1 \\
\hline Quintil 5 & 13,0 & 44,6 & 34,2 & 35,4 & 15,5 & 20,3 \\
\hline \multicolumn{7}{|l|}{ Nacionalidad } \\
\hline Española & 100,0 & 21,6 & 48,6 & 78,2 & 99,7 & 84,1 \\
\hline Europa & 0,0 & 13,4 & 17,1 & 3,5 & 0,1 & 3,5 \\
\hline África & 0,0 & 19,2 & 16,6 & 14,8 & 0,1 & 4,8 \\
\hline América & 0,0 & 31,4 & 14,8 & 0,4 & 0,1 & 5,4 \\
\hline Asia & 0,0 & 14,4 & 2,8 & 3,2 & 0,0 & 2,2 \\
\hline \multicolumn{7}{|l|}{ País de nacimiento } \\
\hline España & 100,0 & 0,0 & 0,0 & 100,0 & 100,0 & 78,1 \\
\hline Europa & 0,0 & 13,3 & 20,2 & 0,0 & 0,0 & 3,7 \\
\hline África & 0,0 & 20,5 & 21,2 & 0,0 & 0,0 & 4,6 \\
\hline América & 0,0 & 50,9 & 50,7 & 0,0 & 0,0 & 10,9 \\
\hline Asia & 0,0 & 15,2 & 7,8 & 0,0 & 0,0 & 2,7 \\
\hline
\end{tabular}

Fuente: elaboración propia. Datos del Departament d'Ensenyament e Idescat. 
Tabla 3.

Fracaso escolar según las características migratorias en el cuarto curso de ESO en las escuelas públicas de Cataluña en 2015-2016

\begin{tabular}{|c|c|c|c|c|c|c|}
\hline & Autóctonos & $\begin{array}{c}\text { Primera } \\
\text { Generación }\end{array}$ & $\begin{array}{c}\text { Generación } \\
1,75 \\
\end{array}$ & $\begin{array}{c}\text { Segunda } \\
\text { Generación }\end{array}$ & $\begin{array}{c}\text { Generación } \\
2,5 \\
\end{array}$ & Total \\
\hline \multicolumn{7}{|l|}{ Sexo } \\
\hline Hombres & 13,3 & 34,8 & 21,7 & 21,3 & 12,6 & 17,5 \\
\hline Mujeres & 7,4 & 23,5 & 12,2 & 13,7 & 7,7 & 10,5 \\
\hline Total & 10,3 & 29,3 & 16,7 & 17,4 & 10,1 & 14,0 \\
\hline \multicolumn{7}{|l|}{ Discontinuidad } \\
\hline Discontinuos & 16,7 & 26,3 & 19,8 & 21,4 & 22,4 & 20,1 \\
\hline No discontinuos & 9,7 & 28,0 & 15,2 & 16,0 & 9,3 & 12,5 \\
\hline \multicolumn{7}{|c|}{ Necesidades Educativas Especiales } \\
\hline Situación social desfavorable & 33,9 & 34,8 & 22,9 & 27,8 & 29,2 & 31,9 \\
\hline \multicolumn{7}{|c|}{ Convivencia con los progenitores } \\
\hline Los dos & 8,0 & 23,9 & 13,9 & 15,1 & 10,3 & 9,9 \\
\hline Madre & 14,2 & 31,4 & 18,9 & 18,0 & 10,0 & 17,1 \\
\hline Padre & 13,4 & 37,1 & 16,3 & 21,5 & 7,9 & 20,2 \\
\hline Otros & 17,0 & 35,3 & 21,8 & 17,4 & 5,9 & 19,4 \\
\hline \multicolumn{7}{|l|}{ Año de llegada a Cataluña } \\
\hline No se ha movido & 10,3 & & & 17,7 & 9,8 & 10,9 \\
\hline Antes de 2006 & & & 17,1 & & & 17,0 \\
\hline Entre 2006 y 2011 & & 22,3 & & & & 21,0 \\
\hline Entre 2011 y 2014 & & 32,2 & & & & 31,1 \\
\hline Último año & & 59,2 & & & & 56,3 \\
\hline \multicolumn{7}{|l|}{ Repetición } \\
\hline Es repetidor & 29,4 & 38,4 & 34,0 & 32,8 & 28,6 & 32,7 \\
\hline \multicolumn{7}{|l|}{ Concentración } \\
\hline Quintil 1 & 8,6 & 23,4 & 12,4 & 15,0 & 7,5 & 9,5 \\
\hline Quintil 2 & 10,1 & 27,5 & 15,2 & 15,6 & 11,0 & 12,0 \\
\hline Quintil 3 & 10,3 & 29,0 & 15,7 & 18,3 & 9,9 & 13,3 \\
\hline Quintil 4 & 11,3 & 32,4 & 17,6 & 16,9 & 10,4 & 15,7 \\
\hline Quintil 5 & 12,6 & 29,1 & 18,5 & 18,5 & 12,6 & 19,4 \\
\hline \multicolumn{7}{|l|}{ Nacionalidad } \\
\hline Española & 10,3 & 21,6 & 15,3 & 16,4 & 10,0 & 11,3 \\
\hline Europa & & 23,1 & 12,3 & 11,0 & & 17,5 \\
\hline África & & 34,0 & 21,6 & 23,2 & & 29,9 \\
\hline América & & 32,0 & 21,3 & & & 32,2 \\
\hline Asia & & 34,8 & 16,9 & 17,6 & & 33,7 \\
\hline \multicolumn{7}{|l|}{ País de nacimiento } \\
\hline España & 10,1 & & & 16,8 & 9,8 & 10,6 \\
\hline Europa & & 21,4 & 12,2 & & & 16,3 \\
\hline África & & 32,2 & 20,0 & & & 28,3 \\
\hline América & & 26,3 & 17,4 & & & 24,2 \\
\hline Asia & & 32,2 & 7,6 & & & 27,1 \\
\hline
\end{tabular}

Fuente: elaboración propia. Datos del Departament d’Ensenyament e Idescat. 
La llegada tardía es determinante en el fracaso escolar. Más de la mitad de los alumnos (el 56,3 $\%)$ que se incorporaron en el último curso no obtienen el graduado escolar, proporción que incluso se incrementa por encima del $80 \%$ en algunos orígenes. Los porcentajes de fracaso disminuyen cuando transcurre más tiempo desde su incorporación al sistema educativo. Generalmente, se considera que la incorporación a edades tempranas comporta pocos riesgos de incremento del fracaso (Corak 2011), como se observa al comparar la generación 1,75 con la segunda generación.

Por detrás del año de llegada, la situación de repetición será la más relacionada con el fracaso para todas las categorías, hecho que cuestiona el éxito de la repetición como estrategia educativa.

De la misma forma, la discontinuidad escolar tiene un efecto muy negativo sobre el fracaso, con independencia del estatus migratorio del alumno. El fracaso escolar entre los que han experimentado una discontinuidad es del $20,1 \%$, frente a un $12,5 \%$ cuando esta no existe. El único caso con un comportamiento divergente es el de la primera generación, en que disminuye el porcentaje de fracaso entre los discontinuos. En esta situación, el fracaso va muy ligado a la llegada reciente, situación en que la discontinuidad, por definición (un año de diferencia entre la primera y última llegada), se ve dificultada entre los de más reciente llegada, e identifica a alumnos que llegaron a Cataluña con menor edad.

En cuanto a la convivencia, todo lo que no sea residir con ambos progenitores se relaciona con mayor fracaso, a excepción de los integrantes de la generación 2,5 , para la que ya se ha avanzado el posible efecto de selección sobre los resultados.

Por lo que se refiere a la concentración escolar, para los alumnos autóctonos se observa que, a mayor concentración, existe un crecimiento del fracaso escolar. Desde porcentajes del 8,6 \% en el primer quintil de concentración a un $12,6 \%$ en los niveles de mayor concentración. A pesar de la existencia de esta correlación, tendría una repercusión menor que la mayoría de las variables utilizadas. Para el resto de los grupos también se observa un efecto negativo de poca intensidad a medida que se incrementa la concentración.

Finalmente, para los grupos de inmigrantes tener la nacionalidad española o de algún país europeo se relaciona con un menor fracaso escolar. Además, a igualdad de estatus migratorio, para los africanos y asiáticos el fracaso es mayor si se observa desde la perspectiva de la nacionalidad en comparación con el país de nacimiento. Esta diferenciación puede considerarse como un efecto selección, desapareciendo de observación aquellos que se nacionalizan.

\section{Resultados de LA REgResión}

El primer modelo multivariable (ver figura 2) recoge hasta nueve variables en el análisis. Entre ellas, el año de llegada a Cataluña es la que interactúa de forma más importante con el fracaso escolar, especialmente en aquellos alumnos que han llegado durante el último año, y que multiplican por 3,5 las probabilidades de fracaso en relación con la categoría de referencia. También si se ha llegado durante la ESO (entre 2011 y 2014) o incluso en primaria (entre 2006 y 2011) se observa un mayor fracaso, aunque con una clara reducción de las probabilidades en comparación con la categoría anterior.

La segunda variable interpretativa es la repetición de curso, que multiplica por 2,6 las probabilidades de fracaso entre los repetidores. Como tercer factor aparece el sexo de los alumnos, con una mayor incidencia en los hombres. La cuarta variable explicativa es la convivencia con los progenitores, en la que se penaliza cualquier tipo de convivencia que se aleje de la de los dos progenitores, en especial si se convive con otras personas. En cuanto a la situación social desfavorable, esta duplica las probabilidades de fracaso en comparación con el resto de alumnos.

Sobre la nacionalidad, en el caso de poseer una europea los valores obtenidos, aunque con menor propensión a no obtener el graduado, no son significativos. En el resto de situaciones siempre es un factor importante, con un aumento del fracaso especialmente entre africanos y asiáticos y, en menor medida, para los nacionales americanos. Por cuestiones de colinealidad no se ha analizado el país de nacimiento, en parte porque esta variable se encuentra recogida en la propia definición del estatus migratorio y en su intersección con el año de llegada, además de su estrecha vinculación, en algunos casos, con la nacionalidad. El estatus migratorio es precisamente la categoría siguiente, con mayores probabilidades de fracaso entre los alumnos de primera generación y los de segunda generación. La generación 1,75 (en la que el alumno ha nacido fuera aunque se ha integrado en el sistema desde un inicio) no muestra resultados significativos, como tampoco lo hace la generación 2,5 . Finalmente, y en contraste con la importancia que se le sugiere, el efecto de la concentración no es muy significativo, aunque creciente a medida que esta se incrementa. Es destacable que existe un efecto relacionado con la menor concentración, afectando de forma negativa la probabilidad de fracaso escolar, es decir, en las escuelas con menor concentración de alumnos relacionados con la inmigración el fracaso escolar es más reducido. El hecho de analizar solo escuelas públicas puede interferir en los resultados obtenidos. La última variable, la discontinuidad, no muestra resultados significativos para el modelo global. 
Figura 2.

Resultados de la regresión logística. Modelo para el total del alumnado de cuarto de ESO en las escuelas públicas de Cataluña en el curso 2015-2016. Variables explicativas del fracaso escolar

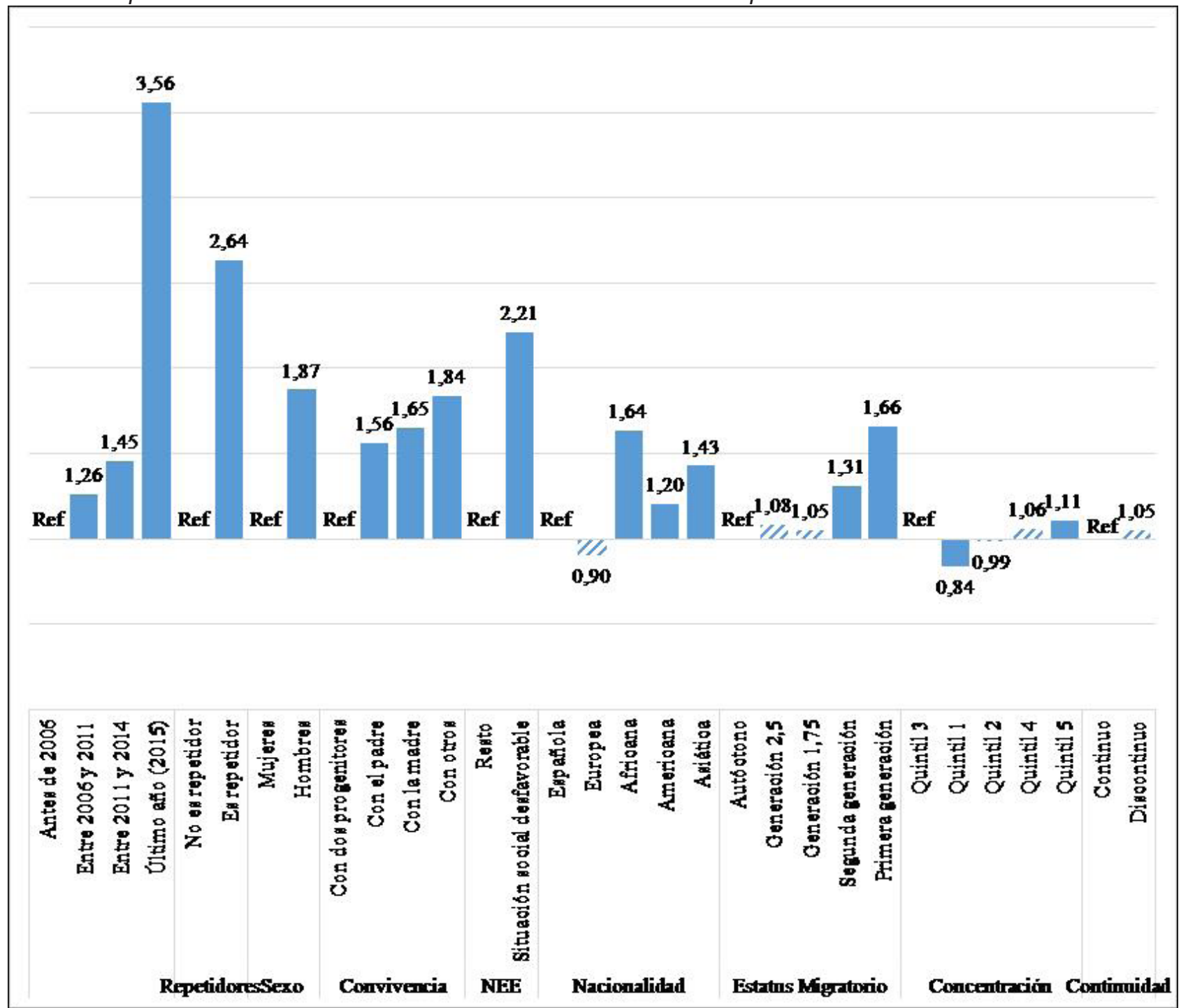

Fuente: elaboración propia. Datos del Departament d'Ensenyament e Idescat, curso 2015-2016. Nota: en colores discontinuos se representan las categorías no significativas.

En un segundo momento se realizan cinco nuevas regresiones logísticas, una para cada categoría relacionada con la migración (tabla 4). Primero se analiza el caso de los alumnos autóctonos. Se trata de 28537 alumnos con toda la información disponible y con un fracaso escolar del 10,3 \%. La repetición de curso y la existencia de una situación social desfavorable son los dos principales elementos que se relacionan con el fracaso. Después aparece el sexo, ya que las chicas obtienen mejores resultados que los chicos. Es también significativa la convivencia con los dos progenitores, ya que el fracaso es mayor en las otras categorías, especialmente si la comparación se realiza con el modelo global. La discontinuidad multiplica también la probabilidad de malos resultados. Finalmente, sigue siendo significativa la concentración para el alumnado autóctono. Si las categorías más próximas a la mediana no son representativas, sí que lo son las dos de valores más extremos. Por tanto, existirá un fracaso escolar más elevado de los alumnos autóctonos en las escuelas con mayor concentración de inmigrantes y a la inversa, aunque con efectos poco significativos en comparación con el resto de variables.

A continuación, se presentan los resultados de las dos categorías de alumnos nacidos en el extranjero. Para la primera generación se cuenta con 4018 casos y se trata del grupo con mayor fracaso escolar, del 29,3 \%. Para la generación 1,75 (que se incorpora al sistema educativo desde sus inicios) se dispone de datos completos para 3130 alumnos y es un grupo con un fracaso del 16,7\%. Entre los alumnos de la primera generación existen varios factores explicativos. En primer lugar, el año de llegada es el elemento más importante, con unos valores muy por encima del resto cuando esta llegada se ha producido durante el último año. La llegada reciente es, por lo tanto, la principal causa que justifica el mayor 
fracaso escolar entre los alumnos de la primera generación, hasta el punto de que, a pesar de formar también parte del modelo, la situación social desfavorable o la repetición no muestran la misma intensidad en la explicación. La misma relevancia que adquiere esta variable (año de llegada) produce que la discontinuidad aparezca con un efecto positivo (inferior a la unidad), es decir, que entre los alumnos de la primera generación esté asociada a mayores rendimientos educativos. En este caso, la discontinuidad y una primera llegada durante el último año no son situaciones compatibles, y, a pesar de la discontinuidad, los resultados alcanzados mejoran a los de los recién llegados. También en este caso, el país de nacimiento es importante, especialmente para los nacidos en África o Asia, doblando las probabilidades de fracaso en comparación con los europeos, mientras que para los nacidos en América no es una situación estadísticamente significativa.

Para la generación 1,75 el fracaso escolar se relaciona, como en los otros grupos, primeramente con la condición de repetidor y, en segundo lugar, con diferencias según el sexo. Para este conjunto de alumnos la nacionalidad interviene en relación con el fracaso, de forma negativa entre los nacionales africanos o asiáticos, en comparación con los europeos. En cambio, según el país de nacimiento, los nacidos en Asia muestran una menor probabilidad al fracaso en relación con los europeos, efecto que se justifica por la perturbación de las adopciones internacionales en esta categoría. Por otro lado, vuelve a aparecer como factor explicativo la convivencia, también cuando solo convive con el padre. Finalmente, en este caso la discontinuidad afecta negativamente al éxito escolar, aunque sin significatividad estadística al controlar el resto de variables.

En las dos categorías relacionadas con la inmigración y con alumnos nacidos en España, en la segunda generación (2084 alumnos, con un fracaso del $17,4 \%$ ), los factores explicativos más relevantes son el encontrarse repitiendo curso, el sexo y la situación social desfavorable, con menor peso de la composición familiar. Presentan, por tanto, prácticamente las mismas variables que los alumnos autóctonos, y resulta relevante que la variable de nacionalidad aparece como explicativa en comparación con la nacionalidad española. Esta agrupación de variables es muy similar a la que se observa para los 1475 alumnos de la generación 2,5 (con un fracaso del $10,1 \%)$. En este último caso, la convivencia no es una variable significativa; en cambio crece el alcance de la situación social desfavorable y la de repetidor, con un panorama muy similar al de los alumnos autóctonos, aunque el efecto de la discontinuidad es, en este caso, mucho más importante.

El resultado de los modelos indica factores compartidos entre los grupos (convivencia, sexo, necesidades educativas, repetición) y factores propios de los grupos relacionados con la migración, en función de la experiencia migratoria de cada alumno. Al mismo tiempo, además de incidir en los factores explicativos, es necesario señalar aquellos factores que no aparecen como determinantes en el modelo. Como ejemplo, la concentración, calculada en relación con el conjunto de escuelas de Cataluña, no interviene de forma significativa en ninguna de las cuatro categorías relacionadas con la migración, aunque sí lo hace para los alumnos autóctonos, sin embargo, con poca intensidad. Finalmente, en las categorías en que se ha migrado directamente, el país de nacimiento en la primera generación o la nacionalidad en la generación 1,75 son importantes, señalando mayores dificultades en algunos orígenes (africanos y asiáticos) y adquiriendo de nuevo importancia la situación familiar, en relación con el propio proceso migratorio.

\section{Conclusiones}

Con relación al primer objetivo de este artículo, el análisis de la composición del alumnado inmigrante según sus vínculos con el proceso migratorio, se ha visibilizado la diversidad de situaciones existente y la creciente primacía de las segundas generaciones en la escuela. Como consecuencia de esta desigual composición por estatus migratorio, podemos apuntar que las demandas educativas derivadas de la diversidad en las aulas conocerán profundas variaciones en los próximos cursos. Independientemente de lo que suceda con las migraciones futuras, la diversidad escolar se encuentra modelada por factores demográficos del pasado (substancialmente migraciones, aunque también la fecundidad), con trayectorias vitales respecto a la inmigración muy diversas, tanto de los alumnos como de los progenitores.

El segundo objetivo era determinar la relación entre estatus migratorio y fracaso escolar. Analizando el alumnado en institutos de titularidad pública, los resultados indican la existencia de una clara correlación entre lugar de nacimiento propio o de los progenitores, año de llegada y éxito académico, en consonancia con la hipótesis planteada. Los peores resultados son para aquellos llegados a una edad tardía (la primera generación, con un $29,3 \%$ de sus integrantes que no obtienen el Graduado en ESO y una diferencia de once puntos entre sexos), a los que siguen la generación 1,75 y la segunda generación. En cambio, los hijos de parejas mixtas muestran resultados equiparables o incluso mejores que los autóctonos. En este contexto, la escuela pública, que virtualmente se presenta como un mecanismo indirecto de redistribución social, en la práctica puede acabar actuando, como indica Bourdieu (1998), como uno de los dispositivos de reproducción de las desigualdades sociales. 
Tabla 4.

Modelos de regresión logística particulares para cada estatus migratorio del alumno en Cataluña en el curso 2015-2016

\begin{tabular}{|c|c|c|c|c|c|c|}
\hline & & Autóctonos & $\begin{array}{c}\text { Primera } \\
\text { Generación }\end{array}$ & $\begin{array}{c}\text { Generación } \\
1,75\end{array}$ & $\begin{array}{l}\text { Segunda } \\
\text { Generación }\end{array}$ & $\begin{array}{c}\text { Generación } \\
2,5\end{array}$ \\
\hline Variables en la ecuación & Categorías & & & Valor $\operatorname{Exp}(B)$ & & \\
\hline \multicolumn{7}{|l|}{ Ref. $=1$} \\
\hline Año llegada a Cataluña & Antes de 2006 & & $1,922^{*}(0,619)$ & & & \\
\hline \multirow[t]{2}{*}{ Entre 2006 y 2011} & Entre 2011 y 2014 & & $1,824^{* * *}(0,166)$ & & & \\
\hline & Último año (2015) & & $4,880^{* * *}(0,533)$ & & & \\
\hline Sexo & Hombres & $1,897^{* * *}(0,079)$ & $1,784^{* * *}(0,133)$ & $1,895^{\star * *}(0,194)$ & $1,691^{* * \star}(0,204)$ & $1,737^{* *}(0,315)$ \\
\hline \multicolumn{7}{|l|}{ Mujeres } \\
\hline Repetidores & Es repetidor & $3,504^{* * *}(0,236)$ & $1,365^{\star *}(0,141)$ & $2,856^{* \star *}(0,454)$ & $2,106^{\star \star \star}(0,448)$ & $3,792^{\star * *}(1,204)$ \\
\hline \multicolumn{7}{|l|}{ No es repetidor } \\
\hline NEE & Sit. social desfavorable & $3,468^{* * *}(0,350)$ & $1,444^{\star *}(0,203)$ & $1,276(0,251)$ & $1,714^{\star *}(0,312)$ & $3,346^{*}(1,600)$ \\
\hline \multicolumn{7}{|l|}{ Resto } \\
\hline Nacionalidad & Europea & & $1,192(0,373)$ & $0,872(0,178)$ & $0,474+(0,208)$ & \\
\hline \multirow[t]{3}{*}{ Española } & Africana & & $1,064(0,316)$ & $1,754^{*}(0,449)$ & $1,603^{* *}(0,250)$ & \\
\hline & Americana & & $1,240+(0,149)$ & $1,219(0,187)$ & $1,507(1,263)$ & \\
\hline & Asiática & & $0,997(0,369)$ & $2,604^{*}(1,263)$ & $0,875(0,328)$ & \\
\hline Continente de nacimiento & África & & $1,927^{* * *}(0,262)$ & $0,936(0,275)$ & & \\
\hline \multirow[t]{2}{*}{ Europa } & América & & $1,182(0,150)$ & $1,132(0,221)$ & & \\
\hline & Asia & & $1,842^{* * *}(0,269)$ & $0,366^{*}(0,149)$ & & \\
\hline Convivencia & Con el padre & $1,627^{* * *}(0,131)$ & $1,471^{\star \star *}(0,155)$ & $1,148(0,192)$ & $1,508^{*}(0,251)$ & $0,700(0,340)$ \\
\hline \multirow[t]{2}{*}{ Con dos progenitores } & Con la madre & $1,815^{\star * *}(0,079)$ & $1,398^{* * *}(0,131)$ & $1,471^{* * *}(0,165)$ & $1,280+(0,175)$ & $0,957(0,230)$ \\
\hline & Con otros & $2,074^{\star * *}(0,208)$ & $1,363(0,278)$ & $1,790 *(0,523)$ & $1,072(0,374)$ & $0,535(0,565)$ \\
\hline Continuidad & Discontinuo & $1,572^{* * *}(0,126)$ & $0,667^{* * *}(0,079)$ & $1,383(0,282)$ & $1,225(0,198)$ & $3,068^{\star \star *}(0,965)$ \\
\hline \multicolumn{7}{|l|}{ Continuo } \\
\hline Concentración & $\begin{array}{l}\text { Muy por debajo de la } \\
\text { media }\end{array}$ & $0,838^{* *}(0,052)$ & $0,948(0,178)$ & $0,809(0,180)$ & $0,796(0,202)$ & $0,767(0,227)$ \\
\hline \multirow[t]{3}{*}{ Media } & Por debajo de la media & $0,981(0,060)$ & $1,089(0,157)$ & $0,997(0,181)$ & $0,769(0,169)$ & $1,058(0,291)$ \\
\hline & Por encima de la media & $1,018(0,064)$ & $1,200(0,145)$ & $1,142(0,177)$ & $0,874(0,162)$ & $1,027(0,281)$ \\
\hline & $\begin{array}{l}\text { Muy por encima de la } \\
\text { media }\end{array}$ & $1,145^{*}(0,078)$ & $1,053(0,115)$ & $1,213(0,175)$ & $0,969(0,165)$ & $1,292(0,369)$ \\
\hline Constante & & $0,054^{* * *}(0,003)$ & $0,087^{* * *}(0,029)$ & $0,047^{* * *}(0,012)$ & $0,120^{\star * \star}(0,021)$ & $0,070^{* * *}(0,017)$ \\
\hline Observaciones & & 28392 & 4018 & 3130 & 2084 & 1468 \\
\hline
\end{tabular}

Nota: error estándar entre paréntesis. Significación: *** $p<0.001,{ }^{* *} p<0.01,{ }^{*} p<0.05,+p<0.1$

Fuente: elaboración propia. Datos del Departament d’Ensenyament e Idescat. 
La relación existente entre fracaso escolar y estatus migratorio comportará cambios relevantes en la incidencia del fracaso en los próximos años, debido a un efecto composición del alumnado, ya que aquellos que han iniciado su ciclo escolar en Cataluña o se encuentran vinculados a través de los proyectos migratorios de sus progenitores aumentaran su peso dentro de la composición del alumnado. Al mismo tiempo, la pausada recuperación de la inmigración que se viene observando desde 2013 representará un aumento de menores inmigrantes en la escuela, con un efecto difícil de determinar.

En cuanto a los determinantes del fracaso, para la mayoría de alumnos aparecen tres situaciones, con independencia del proceso migratorio: 1) la convivencia familiar; 2) la vulnerabilidad social (a partir de las NEE), y 3 ) la repetición de curso, que encubre dificultades previas. Además, aparece siempre un sesgo universal de género, el fracaso está siempre en mayor medida asociado al género masculino. La propia perturbación que representa el fenómeno migratorio (llegada tardía y discontinuidad), se muestra como un factor de riesgo específico entre los menores inmigrantes. Aunque es necesario ahondar en el estudio de los orígenes específicos, la incidencia negativa del origen se relaciona más con las propias estrategias migratorias asociadas a ellos y al capital humano que representa el conocimiento de la lengua castellana que con otros hechos diferenciales. El conocimiento de la lengua para los alumnos latinoamericanos (y para los nacidos en España) es un factor relacionado con la reducción del fracaso. Así se interpretan los mejores resultados de los alumnos latinoamericanos para las generaciones 1 y 1,75 y la desaparición de la significación del origen de los progenitores para las generaciones 2 y 2,5.

Por último, se puede constatar la existencia de una correlación entre concentración (de alumnos relacionados con la inmigración) y rendimiento, especialmente para los alumnos autóctonos. Esta correlación debe ser relacionada con la selectividad negativa de las familias autóctonas con menores recursos económicos en el momento de escoger centro escolar, en un contexto de dualidad entre lo público y lo privado. El efecto barrio relacionado con la concentración es más visible para los autóctonos que para los inmigrantes, ya que para las categorías de inmigrantes el efecto concentración es menos decisivo, e incluso no es significativo cuando se controlan el resto de variables.

\section{Agradecimientos}

Este texto forma parte del proyecto de I+D dirigido por Andreu Domingo "Demografía, migraciones y nuevas fronteras estadísticas: Big Data, Registros continuos de población y Registros administrativos" (CSO2017-85670-R), y del proyecto "Inmigración extranjera, concentración territorial y efecto barrio en España", financiado con una Beca Leonardo para investigadores y creadores culturales de la Fundación BBVA y dirigido por Jordi Bayona.

\section{Notas}

[1] El Registro Continuo de Población es el resultado de relacionar el Padrón Continuo con otros registros administrativos.

[2] En el Padrón Continuo no existe variable alguna que informe de los lazos familiares entre los integrantes de un hogar.

[3] Para un análisis en mayor profundidad sobre este tema, ver García Borrego (2003).

[4] Esto representa únicamente 9066 alumnos extranjeros menos, a pesar del descenso de las entradas de migración internacional por el impacto de la crisis económica.

[5] Como ejemplo, en Cataluña y entre los años 2007 y 2016, hasta 44811 menores de 14 años de nacionalidad extranjera han adquirido la nacionalidad española.

[6] El reciente trabajo de González-Ferrer y Cebolla-Boado (2018) analiza a este colectivo e incide en su crecimiento e importancia en España.

[7] Acrónimo proveniente del inglés Programme for International Student Assessment, programa coordinado desde la OCDE y que mide cada tres años el rendimiento académico de los alumnos en varios países.

[8] La educación obligatoria más el segundo ciclo de infantil, de asistencia generalizada y prácticamente universal.
[9] De estos alumnos se desconoce si han sido escolarizados antes en otras comunidades de España.

[10] En algunos casos, los niños pueden ser enviados al país de origen para posteriormente reincorporarse al sistema educativo español. Estas estrategias, encaminadas a salvaguardar la cultura original, pueden tener efectos significativos sobre el éxito escolar.

[11] La casuística es más compleja (por ejemplo la existencia de hijos de españoles emigrados y después retornados, o de jóvenes adoptados internacionalmente). No se ha querido ahondar más en la clasificación para evitar la dispersión de categorías y su significación estadística. Nótese que no se incorpora la nacionalidad, con lo cual alumnos extranjeros pueden aparecer en la categoría de autóctonos.

[12] Los datos del año 2000 son del Padrón Continuo de población, el resto provienen, en cambio, de las Cifras de Población elaboradas por el Instituto Nacional de Estadística (INE).

[13] La observación de la relación entre sexos existente entre los alumnos de varios cursos nos hace pensar en esta posibilidad.

[14] En las escuelas privadas estos valores son menores. Los porcentajes obtenidos con la base de datos del curso 2015-2016 difieren ligeramente de los publicados en la web del Departament d'Ensenyament. 


\section{ReferenCIAS BiBLIOGRÁficAS}

Albaigés, B. y G. Ferrer-Esteban. 2017. L'estat de l'educació a Catalunya. Anuari 2016. Indicadors sobre l'èxit educatiu a Catalunya. Barcelona: Fundació Jaume Bofill.

Alcalde, R.; J. Bayona.; A. Domingo.; A. González-Ferrer y D. López-Falcón. 2010. El reagrupament familiar a Catalunya. Una aproximació quantitativa, Col·lecció Informes Breus, 23, Barcelona: Editorial Mediterrània y Fundació Jaume Bofill.

Alegre, M.À.; R. Benito y S. González. 2006. Immigrants als instituts. L'acollida vista pels seus protagonistes. Polítiques, 55. Barcelona: Editorial Mediterrània y Fundació Jaume Bofill.

Álvarez, A. 2006. Nacionalidad de los hijos de extranjeros nacidos en España. Madrid: Ministerio de Trabajo y Asuntos Sociales.

Aparicio, R. y A. Portes. 2014. Crecer en España. La integración de los hijos de inmigrantes. Barcelona: Obra Social La Caixa. Colección Estudios Sociales, 38.

Arango, J. 2010. "Después del gran boom: la inmigración en la bisagra del cambio". Pp. 52-73 en La inmigración en tiempos de crisis. Anuario de la inmigración en España, editado por E. Aja, J. Arango y J. Oliver. Barcelona: Fundació CIDOB.

Boertien, D. 2018. “¿Supone la monoparentalidad un riesgo para el rendimiento escolar de los hijos?". Perspectives Demogràfiques 10: 1-4.

Böhlmark, A. 2008. "Age at immigration and school performance: A siblings analysis using swedish register data". Labour Economics 15: 1366-1387. https://doi.org/10.1016/j.labeco.2007.12.004

Bolívar, A. y L. López-Calvo. 2009. "Las grandes cifras del fracaso y los riesgos de exclusión educativa". Profesorado, Revista de Currículim y formación de Profesorado 13(3): 51-78.

Bonal, X., A. Castejón, A. Zancajo y J.L. Castel. 2015. Equitat i resultats educatius a Catalunya. Una mirada a partir de PISA 2012. Barcelona: Fundació Jaume Bofill. Informes breus, 60 .

Bourdieu, P. 1998. Capital cultural, escuela y espacio social. México: Siglo XXI

Calero, J., A. Choi y S. Waisgrais. 2010. "Determinantes del riesgo de fracaso escolar en España: una aproximación a través de un anàlisis logístico multinivel aplicado a PISA-2006". Revista de Educación número extraordinario: $225-256$.

Calero, J. y J. O Escardíbul. 2016. "Proceso educativo y resultados del alumnado nativo y de origen inmigrante en España. Un anàlisis basado en PISA-2012". Estudios de Economía Aplicada 34(2): 413-438.

Carrasco, S. 2003. "La escolarización de los hijos e hijas de inmigrantes y de minorías étnico-culturales". Revista de Educación 330: 99-136.

Cea d'Ancona, M.A. y M. Valles. 2014. Evolución del racismo, la xenofobia y otras formas conexas de intolerancia en España. Madrid: Ministerio de Empleo y Seguridad Social.

Cebolla-Boado, H. y L. Garrido. 2011. "The impact of Immigrant Concentration in Spanish Schools: School, Class, and Composition Effects". European Sociological Review 27(5): 606-623. https://doi.org/10.1093/esr/jcq024
Choi, A. y J. Calero. 2013. "Determinantes del riesgo de fracaso escolar en España en PISA-2009 y propuestas de reforma”. Revista de Educación 362: 562-593.

Colectivo IOE. 2003. "Alumnos y alumnas de origen extranjero: Distribución y trayectorias escolares diferenciadas". Cuadernos de Pedagogía 326: 63-68.

Coleman, J.S. 1966. Equality of Educational Opportunity. Washington: US Department of Health, Education and Welfare Office of Education.

Corak, M. 2011. "Age at immigration and the education outcomes of children". Discussion Paper series, Forschungsinstitut zur Zukunft der Arbeit, n. 6072, Institute for the Study of Labor (IZA), Bonn.

Departament d'Ensenyament de la Generalitat de Catalunya, 2013. Ofensiva de país a favor de l'èxit escolar. Pla per a la reducció del fracàs escolar a Catalunya, 20122018. Barcelona: Departament d'Ensenyament. Generalitat de Catalunya.

Domingo, A. y J. Bayona. 2010. "Los hogares de la población de nacionalidad extranjera en España en el año 2001". Papers de Sociologia 95(3): 731-754. https://doi. org/10.5565/rev/papers/v95n3.65

Domingo, A. y J. Bayona. 2016. "Panoràmica de la immigració a Catalunya". Pp. 10-45 en Informe sobre la integració de les persones immigrades a Catalunya 2015, coordinado por G. Pinyol-Jiménez. Barcelona: Secretaria d'Igualtat, Migracions i Ciutadania, Generalitat de Catalunya.

Domingo, A. y A. Cabré. 2015. "La demografía del siglo XXI: evolución reciente y elementos prospectivos". Pp. 6373 en España 2015. Situación social, editado por C. Torres. Madrid: Centro de Investigaciones Sociológicas (CIS).

Domingo, A., D. López-Falcón y J. Bayona. 2010. "Reagrupación familiar en la provincia de Barcelona, 2004-2008". Migraciones 27: 11-47.

Fernández Enguita, M., L. Mena y J. Riviere. 2010. Fracaso y abandono escolar en España. Barcelona: Fundació La Caixa, Colección Estudios Sociales, 29.

Fernández González, J.J. y J.C. Rodríguez Pérez. 2008 "Los orígenes del fracaso escolar en España. Un estudio empírico". Mediterráneo Económico 14: 323-349.

Fernández-Mellizo, M. y J.S. Martínez-García. 2017. "Inequality of educational opportunities: School failure trends in Spain (1977-2012)". International Studies in Sociology of Education 26:3: 267-287. https://doi.org/10.1080/09 620214.2016 .1192954

García Ballesteros, A., B.C. Jiménez Blasco y M.M. Mayoral. 2014. "Emigración de retorno y crisis en España". Scripta Nova. Revista Electrónica de Geografía y Ciencias Sociales XVIII(491). Consulta 23 de abril 2018 (http://www.ub.es/geocrit/sn/sn-491.htm).

García Borrego, I. 2003. "Los hijos de inmigrantes como tema sociológico: la cuestión de 'La Segunda Generación'”. Anduli: revista andaluza de ciencias sociales 3: 27-46.

García Castaño, F.J., M. Rubio y O. Bouachra. 2008. "Población inmigrante y escuela en España. Un balance de investigación". Revista de Educación 345: 23-60.

Garrido, L. y H. Cebolla-Boado. 2010. "Rendimiento educativo y concentración de inmigrantes en las escuelas españolas: PISA 2006". Presupuesto y Gasto Público 61: 159-176. 
Gil-Hernández, C.J. y P. Gracia. 2018. "Adolescents' educational aspirations and ethnic background: The case of students of African and Latin American migrant origins in Spain." Demographic Research 38(23): 577-618. https://doi.org/10.4054/demres.2018.38.23

González-Ferrer, A. y H. Cebolla-Boado. 2018. "Los hijos de la inmigración en España: valores, aspiraciones y resultados". Pp. 111-163 en Informe España 2018, coordinado por A. Blanco et al. Madrid: Universidad Pontificia Comillas, Cátedra J.M. Martín Patino.

Huguet, A. y J.L. Navarro. 2006. "Inmigración y resultados escolares: lo que dice la investigación (Presentación del Monográfico)". Cultura y Educación: Culture and Education 18(2): 117-126. https://doi. org/10.1174/113564006777973879

Huguet, A., J.L. Navarro y J. Janés. 2007. "La adquisición del castellano por los escolares inmigrantes. El papel del tiempo de estancia y la lengua familiar". Anuario de psicología / The UB Journal of psychology 38(3): 357375.

López-Falcón, D. y J. Bayona. 2012. "Segregación escolar y residencial en Barcelona: del boom migratorio al asentamiento". Pp. 21-42 en Segregaciones y construcción de la diferencia en la escuela, editado por F.J. García Castaño y A. Olmos. Granada: Editorial Trotta.

Martínez García, J.S. 2009. "Fracaso escolar, PISA y la difícil ESO". RASE, Revista de Sociología de la educación, 2(1): 56-85.
McLanahan, S., L. Tach y D. Schneider. 2013. "The causal effects of father absence". Annual Review of Sociology 39, 399427. https://doi.org/10.1146/annurev-soc-071312-145704

Miguel, V. de y M. Solana. 2017. "Immigrants in the Educational System in Spain: Who Persists?". Social Indicators Research 132: 733-755. https://doi.org/10.1007/s11205-016-1323-4

Murillo, F.J. y C. Martínez-Garrido. 2018. "Magnitud de la segregación escolar por nivel socioeconómico en España y sus Comunidades Autónomas y comparación con los países de la Unión Europea". Rase, Revista de Sociología de la educación 11(1): 37-58. https://doi. org/10.7203/RASE.11.1.10129

OCDE 2016. PISA 2015. Resultados Clave. Consulta 30 de noviembre 2017 (https://www.oecd.org/pisa/pisa2015-results-in-focus-ESP.pdf).

Ortega-Rivera, E., A. Domingo y A. Sabater. 2016. "La emigración española en tiempos de crisis y austeridad". Scripta Nova, Revista de Geografía y Ciencias Sociales 20(549-5).

Rumbaut, R. 2004. "Ages, Life Stages, and Generational Cohorts: Decomposing the Immigrant First and Second Generations in the United States". International Migration Review 38(3): 1160-1205. https://doi. org/10.1111/j.1747-7379.2004.tb00232.x

Síndic de Greuges 2016. La segregació escolar a Catalunya (I): la gestió del procés d'admissió d'alumnat. Juliol 2016. Barcelona: Síndic de Greuges.

JORDI BAYONA-I-CARRASCO es investigador del Centre d'Estudis Demogràfics y profesor asociado al Departamento de Geografía de la Universidad de Barcelona (UB). Es licenciado en Geografía (UB) y doctor en Demografía (UAB). Su investigación se centra en el análisis demográfico de la inmigración internacional y de las pautas de segregación y concentración territoriales de la población extranjera.

ANDREU DOMINGO es doctor en Sociología, investigador y subdirector del Centre d'Estudis Demogràfics (CED) y profesor asociado al Departamento de Geografía de la Universitat Autònoma de Barcelona (UAB). Especializado en migraciones internacionales, formación de la familia y teoría sobre la población. Investigador Principal del Grup d'Estudis de Demografia i Migracions (GEDEM, http://gedemced.uab.cat/es), reconocido como grupo de investigación consolidado por la Generalitat de Cataluña.

TERESA MENACHO es licenciada en Matemáticas, especialidad Estadística e Investigación Operativa, por la Universidad de Sevilla. Es responsable del Banco de Datos, de la Protección de Datos y de la Informática del Centre d’Estudis Demogràfics, y colabora como técnica de apoyo a la investigación, principalmente en temas de proyecciones y estimaciones de población. 